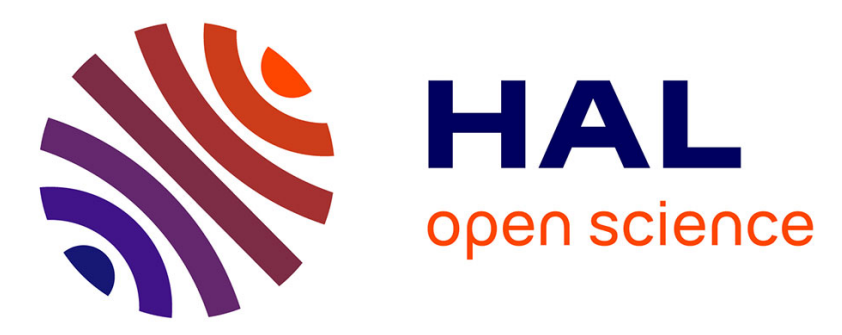

\title{
CFD-based scale-up of hydrodynamics and mixing in bubble columns
}

\author{
L. Gemello, V. Cappello, F. Augier, D. Marchisio, C. Plais
}

\section{To cite this version:}

L. Gemello, V. Cappello, F. Augier, D. Marchisio, C. Plais. CFD-based scale-up of hydrodynamics and mixing in bubble columns. Chemical Engineering Research and Design, 2018, 136, pp.846-858. 10.1016/j.cherd.2018.06.026 . hal-01952005

\section{HAL Id: hal-01952005 https://hal-ifp.archives-ouvertes.fr/hal-01952005}

Submitted on 11 Dec 2018

HAL is a multi-disciplinary open access archive for the deposit and dissemination of scientific research documents, whether they are published or not. The documents may come from teaching and research institutions in France or abroad, or from public or private research centers.
L'archive ouverte pluridisciplinaire HAL, est destinée au dépôt et à la diffusion de documents scientifiques de niveau recherche, publiés ou non, émanant des établissements d'enseignement et de recherche français ou étrangers, des laboratoires publics ou privés. 


\title{
CFD-based scale-up of hydrodynamics and mixing in bubble columns
}

\author{
L. Gemello a,b, V. Cappello ${ }^{\text {a }}$, F. Augier ${ }^{\text {a }}$, D. Marchisio ${ }^{\text {b }}$, C. Plais ${ }^{\text {a }}$ \\ ${ }^{a}$ IFP Energies nouvelles, Rond-point de l'échangeur de Solaize, 69360 Solaize (69), France \\ ${ }^{b}$ Dipartimento di Scienza Applicata e Tecnologia, Politecnico di Torino, Corso Duca degli Abruzzi 24, 10129 Torino (TO), Italy
}

\begin{abstract}
Unsteady and three-dimensional Eulerian-Eulerian CFD simulations of bubble column reactors under operating conditions of industrial interest are discussed in this work. The flow pattern in this equipment depends strongly on the interactions between the gas and liquid phases, mainly via the drag force. In this work, a correlation for the drag force coefficient is tested and improved to consider the so-called swarm effect, that modifies the drag force at high gas volume fractions. The improved swarm factor proposed in this work is the adjustment of the swarm factor proposed by Simonnet et al. (2008). This new swarm factor is suitable for very high gas volume fractions without generating stability problems, which were encountered with the original formulation. It delivers an accurate prediction of gas volume fraction and liquid velocity in a wide range of tested operating conditions. Results are validated by comparison with experimental data on bubble column reactors at different scales and for several operating conditions. Hydrodynamics is well predicted for every operating condition at different scales. Several turbulence models are tested. Finally, the contribution of Bubble Induced Turbulence (BIT), as proposed by Alméras et al. (2015), on mixing is evaluated via an analysis of the mixing time.
\end{abstract}

Keywords: Bubble column, Heterogeneous regime, Drag force, Swarm factor, Mixing, Turbulence

\section{Introduction}

Gas-liquid reactors play a key role in several chemical processes and among them bubble column reactors are particularly important. In these reactors, gas bubbles form the disperse phase and the liquid constitutes the continuous one. Bubble column reactors have a simple geometry without moving parts: gas bubbles are often injected at the bottom of the column and they rise throughout the liquid, exchanging mass, momentum and energy. These reactors are used in different chemical processes such as oxidation, hydrogenation, Fischer-Tropsch synthesis, chemicals production, coal liquefaction and fermentation. These systems have also been used to cell cultures and wastewater treatments. All these industrial processes require effective mass, momentum and energy transfers between the continuous and the disperse phases. Although bubble column reactors appear simple, their modeling is difficult. Hydrodynamics can be complex and strongly dependent on geometry, on fluid flow rates and on the presence of internals. Accordingly, hydrodynamic models are required to predict their global performances. Local and global properties such as phase velocities, flow pattern, turbulence, gas hold-up and bubble size are linked to the operating conditions and the design variables in a complex way.

Industrially bubble column reactors often operate in the heterogeneous churn-turbulent flow regime, therefore it is important to study these systems under these operating conditions. As well-known, under these conditions, local profiles of the properties of interest depend strongly on the radial position. Models for the simulation of bubble column reactors with a larger range of validity (i.e. for both homogeneous and heterogeneous regime) should be developed. CFD simulations are a valid tool for the study of large bubble columns in high gas-hold-up condition. A good choice is to model turbulence at every scale with timeaverage equations and to use the Eulerian-Eulerian multiphase model, with which the phases in the system are described as inter-penetrating continua (Zhang, 2007; Vaidheeswaran and de Bertodano, 2017). This is usually done with the Reynolds-averaged Navier-Stokes equations (RANS) approach. The interactions between the continuous and the disperse phases must be accurately modeled, as stated by Jakobsen et al. (2005) and McClure et al. (2013). Different interfacial forces charac- 
terize the interactions (Hlawitschka et al., 2017); among these, the drag force is the most important. In the heterogeneous regime, the distance between bubbles is small and the boundary layers of the bubbles interact with each other modifying the drag force. This phenomenon is known as the swarm effect. In literature, several swarm factors have been proposed. Some of them are suitable for low gas volume fractions, while for high gas volume fractions very few correlations have been developed (e.g. McClure et al. (2017b)). The existing swarm factors are often empirical or obtained with DNS simulations. They usually have a narrow range of validity and they are based on experiments conducted under homogeneous regimes. As a consequence, their validity in the heterogeneous regime is not established yet.

Buoyancy and interfacial forces depend strongly on local bubble diameters. When the gas volume fraction increases, measuring the bubble size by using non-invasive techniques becomes more and more difficult, because of the opacity of the flow. In addition, the trajectory of the bubbles becomes chaotic, which makes the use of multi-probe techniques inappropriate (Raimundo, 2015). Therefore, until recently there were only a few studies concerning bubble size measurement under heterogeneous regime (Xue, 2004; Chaumat et al., 2007; McClure et al., 2016), especially regarding bubble columns of diameters larger than $0.2 \mathrm{~m}$. A new measurement technique has been recently developed to measure the bubble size in the heterogeneous regime (Raimundo et al., 2016). The cross-correlation technique provides a mean Sauter diameter at any radial position. This method is complementary to the existing ones: it provides a correct mean bubble size measurement for every column position, whereas multiprobe techniques deliver bubble chord distributions, but with acceptable confidence only the central region of the columns where bubble velocities are mainly vertical (Chaumat et al., 2007). Therefore, original data can be acquired and used in order to validate the interaction forces models.

In order to study and validate a drag law expression, including swarm factor, experimental data from a previous work (Raimundo, 2015), have been completed with new experiments in a wide range of superficial gas velocities, going from $0.03 \mathrm{~m} / \mathrm{s}$ to $0.35 \mathrm{~m} / \mathrm{s}$. Global and local gas volume fractions, gas and liquid velocities and bubble size are measured in bubble columns of different diameters $(0.15 \mathrm{~m}, 0.4 \mathrm{~m}, 1 \mathrm{~m}$ and $3 \mathrm{~m})$. These experimental measurements allow to validate CFD simulations at different scales and draw conclusions on the capability of CFD to scale up gas-liquid reactors. The ability of CFD to simulate bubble columns at different scales is a prerequisite for its use at even larger scales, which is the global aim of the present development.

Besides interfacial forces, another important point, for obtaining reasonable results in the simulation of bubble columns operating under the heterogeneous regime, is the choice of the turbulence model. Classical turbulence models are based on the hypothesis of Boussinesq (1897). The turbulence model influences the turbulent mixing, that is a key property for bubble column reactors. In this work four different turbulence models are compared: standard k- $\varepsilon$, RNG k- $\varepsilon$, realizable k- $\varepsilon$ and k- $\omega$ model, as well as the effect that turbulence has on the mixing intensity.

The turbulence model is important not only to predict hydrodynamics, but also to properly predict turbulent mixing of the involved scalars, namely enthalpy and reactant concentrations (Shaikh and Al-Dahhan, 2013). In this work the contribution of bubble-induced turbulence (BIT) to mixing is also considered, as it has been shown in a previous work that BIT impacts strongly the mixing in bubble flows operated at low superficial gas velocity (Alméras et al., 2016). Different strategies can be followed to include BIT in a RANS model. Source terms can be directly added in the k and $\varepsilon$ (or $\omega$ ) transport equations to introduce the turbulence produced by bubbles relative motion (Pfleger and Becker, 2001; Yao and Morel, 2004; Rzehak and Krepper, 2013). Fletcher et al. (2017) and McClure et al. (2017a) pointed out the ability of this approach to predict mixing in industrial bubble columns and airlift reactors. However, the contribution of the BIT to the Reynolds stress tensor, and its diffusive "viscous" effect on the average velocities is not well-understood. Including BIT contributions in the turbulence transport equations implies that this contribution is considered to have similar diffusive properties to shear-induced turbulence (SIT). In the present study, it is preferred to neglect the possible contribution of BIT on turbulent viscosity, without adding any source term in the turbulence transport equations. (Alméras et al., 2015) studied the role of BIT on the mixing in bubbly flows, concluding that, for the investigated system, BIT has an influence on the dispersion of a passive scalar. They characterized the contribution of bubble wake interactions with a diffusive model, adding an extra diffusivity, due to BIT, to the scalar transport equations.

In the first part of this work, the existing drag laws and swarm corrections are tested and modified. A swarm correction suitable for different flow regimes and for different bubble columns is obtained. In the second part, different turbulence models are tested and the BIT contribution is added, in order to improve the simulation 
of mixing in bubble columns.

\section{Experimental setup}

Experiments are conducted in four cylindrical bubble column reactors of different size in a wide range of superficial gas velocities, from $0.03 \mathrm{~m} / \mathrm{s}$ to $0.35 \mathrm{~m} / \mathrm{s}$. The expected flow regimes, for the studied cases, are pseudo-homogeneous flow regime and heterogeneous regime.

Every experiment is carried out at atmospheric pressure with air and tap water. The experimental data for the four columns were collected by Raimundo (2015), while additional data concerning the column $\phi 0.4 \mathrm{~m}$ was collected by Gemello et al. (2018). The data collected by Gemello et al. (2018) is consistent with the data proposed by Raimundo (2015) and more spatial positions are investigated, by using different water qualities. The initial height of liquid inside every column (without gas) is equal to four diameters. The total height of the columns is about eight diameters, allowing to work with very high gas volume fraction. No liquid is withdrawn from the system. The gas is injected through perforated spargers with small holes: the diameter of the holes is $1 \mathrm{~mm}$ for the column $\phi 0.15 \mathrm{~m}, 2$ $\mathrm{mm}$ for the columns $\phi 0.4 \mathrm{~m}$ and $\phi 1 \mathrm{~m}$ and $9 \mathrm{~mm}$ for the column $\phi 3 \mathrm{~m}$ (see Raimundo (2015) and Gemello et al. (2018) for details). These gas distributors ensure a near-homogeneous gas distribution for every column (Raimundo, 2015).

Gas hold-up measurements are carried out by computing the difference of liquid height before and after gas injection. The local gas volume fraction is calculated by using an optical probe (Raimundo, 2015). The axial liquid velocity can be obtained by using a modified Pitot tube, called Pavlov tube (see Forret (2003) for details). The bubble size is measured using the spatial cross-correlation (CC) of two optical probe signals. This method allows to obtain the mean Sauter diameter for high gas volume fractions and for the heterogeneous regime, as established by Raimundo (2015) and Raimundo et al. (2016). These local properties are measured in a wide range of superficial gas velocities for different axial and radial positions.

Experimental results are used to validate CFD simulations. Gas hold-up, local gas volume fraction and axial liquid velocity are detailed in the Results and discussion section with a view to comparing them with CFD results. The bubble size cannot be compared with the CFD simulations: classical CFD simulations considers a fixed bubble size as input parameter. Experiments provide a mean Sauter diameter that ranges from $5 \mathrm{~mm}$ to
8 mm (see Raimundo (2015), Raimundo et al. (2016) and Gemello et al. (2018) for details). The radial profile of the mean Sauter diameter has a quadratic shape in the case of heterogeneous regime. At the center of the column, the mean Sauter diameter increases when the superficial gas velocity increases.

The bubble shape was experimentally obtained by Raimundo (2015) and is in accordance with the bubble shape predicted using the Grace diagram (Clift et al., 1978) and the terminal velocity diagram of Clift et al. (1978) (Fig. 2b). Bubbles are ellipsoidal when their diameter is higher than $1 \mathrm{~mm}$.

\section{CFD simulations}

For studying high gas volume fraction systems under the heterogeneous regime, the simulations ought to be transient and three-dimensional (3D), since the movement of the bubble plume is chaotic (Ekambara et al., 2005).

The Euler-Euler approach is adopted: the two phases are considered as interpenetrating continua. The Eulerian model solves momentum and continuity equations for each phase. Different two-equation turbulence models are tested.

\subsection{Interfacial forces}

Interfacial forces dominate gas-liquid systems (Tabib et al., 2008). The drag force is the most important interaction force in the case of bubble column reactors. The drag force is activated and several drag laws are tested.

It is important to stress here that including additional interfacial forces to the drag force in the heterogeneous regime is still an open question. It has been found by some authors that the lift force can be very helpful when two-dimensional simulations are performed (Joshi, 2001). Lift force can be important in a wallpeaked gas volume fraction distribution linked to a boiling flow, due to the presence of shear flows, as suggested by Sugrue (2017). On the other hand, McClure et al. (2013) found lift force effect as being negligible under the heterogeneous regime for three-dimensional simulations. Finally, as the expression of the lift force coefficient at high gas fraction is still debated, and as acceptable results are obtained without including it, the lift force has not been considered in the present study. This is done also with the objective to simplify as much as possible the final CFD model. Other forces, as virtual mass and wall lubrication force are ignored for similar reasons. 


\subsubsection{Drag law correlations}

The drag law must be studied in detail since it influences the calculation of the relative velocity of the bubbles and, consequently, the gas volume fraction in the column. In the literature, several drag correlations for different operating conditions are reported, valid for example for spherical and deformed bubbles and for pure and contaminated water.

Drag laws suitable for distorted particle regime were proposed by Grace et al. (1976) and Ishii and Zuber (1979). For a deformed bubble, the drag coefficient depends on the Reynolds, the Eötvös and the Morton numbers. In certain cases, some authors use also the Weber number or the Froude number. Both these numbers can be written as a function of the Reynolds, Eötvös and Morton number.

One of the most popular drag laws is the one proposed by Tomiyama (1998):

$$
C_{D}^{\infty}=\max \left\{\min \left\{\frac{24}{R e_{b}}\left(1+0.15 R e_{b}^{0.687}\right), \frac{72}{R e_{b}}\right\}, \frac{8}{3} \frac{E o}{(4+E o)}\right\},
$$

where $C_{D}^{\infty}$ is the drag coefficient for an isolated bubble.

This equation is valid for spherical and ellipsoidal bubbles. It can be used for slightly contaminated airwater systems and similar equations are suitable for different levels of water contamination: three different correlations are proposed by Tomiyama (1998) for pure water, slightly contaminated water and fully contaminated water.

Alternatively, Zhang et al. (2006) suggest a more compact correlation that gives very similar results:

$$
C_{D}^{\infty}=\frac{2}{3} \sqrt{E o} .
$$

This drag law leads to a terminal bubble velocity that does not depend on the bubble size if the bubble diameter ranges from 5 to $8 \mathrm{~mm}$. The drag laws proposed by Zhang et al. (2006) and Tomiyama (1998) give similar results in the studied range. The drag law for oblate bubbles proposed by Tomiyama (1998) has the advantage of considering also the water contamination effects, which are very important in industrial systems. Furthermore, it has a larger range of validity. Therefore, the drag law of Tomiyama (1998) is preferable and it is used in this work.

\subsubsection{Swarm factor}

The correlations described before are valid for isolated bubbles rising through the column and therefore they can only be employed to describe flows characterized by low gas volume fractions. Since high gas volume fractions are considered in this work, it is necessary to use a correction term, called swarm factor $h$, equal to $C_{D} / C_{D}^{\infty}$, where $C_{D}$ is the real drag force that acts on a bubble in the actual operating conditions.

Different swarm factors have been proposed. The first swarm factor expressions had the following form:

$$
h=\left(1-\alpha_{g}\right)^{n},
$$

where $n$ varies for different authors and it is often obtained with a least-squares fit.

Bridge et al. (1964), Wallis (1969), Ishii and $\mathrm{Zu}-$ ber (1979), Rusche and Issa (2000) and Roghair et al. (2011) proposed swarm factors for different operating conditions. These swarm factors generally hinder the bubble rise, increasing the effect of the drag force for high gas volume fraction, with a swarm factor higher than the unity. Some of these swarm factors are reported in Fig. 1.

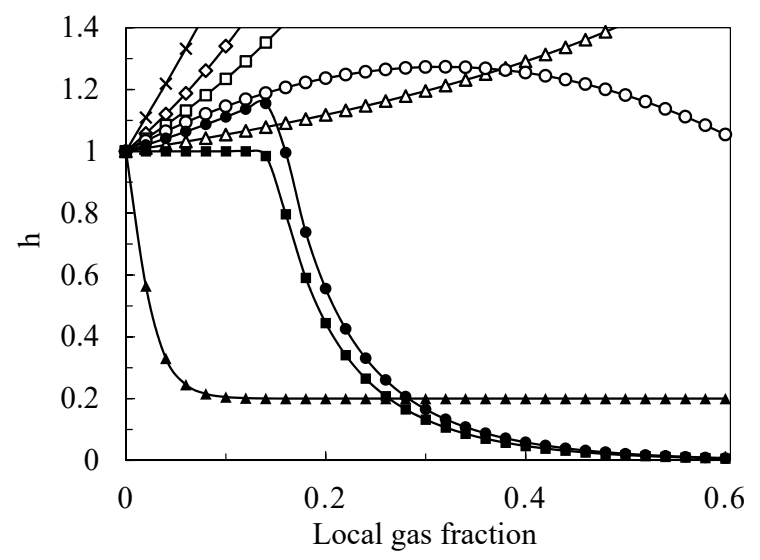

Figure 1: Swarm factors in function of the gas volume fraction: Bridge et al. (1964) $(\diamond)$, Wallis (1969) ( $\square)$, Ishii and Zuber (1979) $(\triangle)$, Rusche and Issa (2000) (×), Simonnet et al. (2008) (๑), Roghair et al. (2011) (○), McClure et al. (2014) (ם) and McClure et al. (2017b) $(\boldsymbol{\Delta})$.

Simonnet et al. (2008) propose an expression in order to consider the existence of a critical value of gas volume fraction of $15 \%$, above which the swarm factor starts to decrease. This empirical correlation is completely different from the traditional ones, as shown in Fig. 1. The authors assert that this swarm factor is validated for a gas volume fraction lower than $30 \%$.

$$
h=\left(1-\alpha_{g}\right)\left[\left(1-\alpha_{g}\right)^{25}+\left(4.8 \frac{\alpha_{g}}{1-\alpha_{g}}\right)^{25}\right]^{-\frac{2}{25}} .
$$

McClure et al. (2014)) propose a modified form of the 
term developed by Simonnet et al. (2008):

$$
h=\left\{\begin{array}{lll}
\min \left(h^{\prime}, 1.0\right) & \text { for } & h^{\prime}>1.0 \\
0.8 h^{\prime} & \text { for } & h^{\prime}<1.0
\end{array}\right.
$$

where $h^{\prime}$ is the original swarm factor proposed by $\mathrm{Si}^{-}$ monnet et al. (2008).

Alternatively, McClure et al. (2017b) suggest an empirical swarm factor available for volume fractions greater than 0.25 :

$$
h=\min \left(\left(1-\alpha_{g}\right)^{n}+b, 1\right),
$$

where $n$ and $b$ are empirical constants obtained with a least-squares fit of their data. McClure et al. (2017b) suggest of using $n$ equal to 50, while $b$ depends on the sparger geometry.

It is important to stress here that most of these correlations have been proposed for the air-water system, therefore there is no proof that their functional form has a general validity.

\subsection{Mixing time}

The global mixing time is computed using the variance method (Paul et al., 2004). As mixing is a continuous process, it is convenient to define the mixing time corresponding to at a certain level of homogeneity. A mean deviation of $5 \%$ from the final concentration is adopted in the present work. The normalized concentration, defined as the ratio $C(t) / C_{D}^{\infty}$, is independent on the volume defined for introducing the scalar. In order to simulate the mixing of a scalar quantity, a User Defined Scalar (UDS) transport equation has to be added in the solver and the diffusion coefficient and source term specified. No generation of scalar is required and the diffusion coefficient $\left(\Gamma_{q}\right)$ considers the molecular $\left(D_{m, q}\right)$ and the turbulent $\left(D_{t, q}\right)$ diffusivity.

$$
\Gamma_{q}=\left(D_{m, q}+D_{t, q}\right)
$$

For each column size, a tracer volume of $0.025 \%$ of the water volume is patched on a cube made of four cells, at the center of the column and at a height equal to five times the diameter. The turbulent diffusivity is classically linked to the turbulent viscosity by means of the dimensionless turbulent Schimdt number $\left(S c_{t}\right)$. A constant value of 0.7 for the turbulent Schimdt number is used in every simulation. In addition to the Shear-Induced Turbulence (SIT) contribution, the contribution of the bubble wakes (BIT) is considered. The anisotropic diffusive model proposed by Alméras et al.
(2016) is used. They model the turbulent mixing due to the bubbles as a regular diffusion phenomenon, so an extra diffusivity $\left(D_{i, i}\right)$ is added. This diffusion coefficient, along the axial direction, is almost of twice the diffusivity in the horizontal direction, because of the anisotropy of the velocity fluctuations. The diffusion model proposed by Alméras et al. (2016) is based on the experimental analysis of the mixing of a low-diffusive scalar; this is a passive scalar that does not influence the flow field.

$$
D_{t, q}=\frac{\mu_{t, q}}{\rho_{q} S c_{t}}+D_{i, i},
$$

where $\mu_{t, q}$ is the turbulent viscosity and $\rho_{q}$ is the density.

According to Alméras et al. (2016), the turbulent diffusivity due to the bubbles is expressed as:

$$
D_{i, i}= \begin{cases}D_{i, 0} \alpha_{g}^{0} .5 & \alpha_{g} \leq \alpha_{g c, i} \\ \beta \gamma_{i}^{2} U_{R} d & \alpha_{g}>\alpha_{g c, i}\end{cases}
$$

where $U_{R}$ is the relative velocity between gas and liquid (measured in $\mathrm{m} / \mathrm{s}$ ), $d$ is the bubble diameter (in $\mathrm{m}$ ). $D_{i, 0}$, $\alpha_{g c, i}, \beta$ and $\gamma_{i}$ are constants, whose values are listed in Table 1 .

\begin{tabular}{ccccccc}
\hline$D_{x, 0}$ & $D_{z, 0}$ & $\alpha_{g c, x}$ & $\alpha_{g c, z}$ & $\beta$ & $\gamma_{x}$ & $\gamma_{z}$ \\
\hline 0.0029 & 0.0045 & 0.027 & 0.041 & 25 & 0.13 & 0.18 \\
\hline
\end{tabular}

Table 1: Parameters of the Alméras et al. (2016) diffusivity model, where $x$ is the horizontal direction and $z$ the vertical one.

$\alpha_{g c, i}$ is a critical value that splits the dependence in two regimes: one at low gas hold-up, in which the diffusivity depends on the gas volume fraction and it scales on the gas volume fraction as $\alpha_{g}^{0.5}$ and a regime at large hold-up, in which diffusivity does not depend on the gas volume fraction, but solely on $U_{R} d$. As it can be seen in Table 1, the transition between these two regimes occurs at a higher hold-up in the vertical direction than in the horizontal one. See Alméras et al. (2015) for details.

\subsection{Test cases and CFD setup}

The simulations are carried out by using a twofluid model (Jakobsen et al., 2005). Reynoldsaveraged Navier-Stokes (RANS) equations are solved; the Eulerian-Eulerian multiphase approach is adopted, so the two phases are considered as interpenetrating continua (Alméras et al., 2016). Turbulence can be described using different approaches and in this work different two-equation models are tested.

Three-dimensional CFD simulations are carried out on four columns of different diameters $(0.15 \mathrm{~m}, 0.4 \mathrm{~m}$, 
$1 \mathrm{~m}$ and $3 \mathrm{~m}$ ) with a superficial gas velocity that ranges from $0.03 \mathrm{~m} / \mathrm{s}$ to $0.35 \mathrm{~m} / \mathrm{s}$. Instantaneous properties must be averaged over a sample time, that can vary from a few seconds up to $100 \mathrm{~s}$ depending on the operating conditions and the studied properties. As a precautionary measure, every simulation is sampled over a period of $100 \mathrm{~s}$. Sampling begin after simulations have reached hydrodynamic equilibrium, neglecting the initial transient.

CFD simulations are carried out with Ansys Fluent 15.0. The multiphase Eulerian model and the Phase Coupled SIMPLE algorithm (PC-SIMPLE) are used to handle the pressure-velocity coupling. A first-order Euler implicit temporal discretization scheme is used. For the gradients calculation, a Green-Gauss node-based formulation is considered. For momentum and volume fraction, the QUICK method is chosen. For the scalar, the second-order upwind method is used. The first-order upwind is used for the turbulence. Secondorder schemes are tested instead of first-order schemes for turbulence and temporal discretization scheme: numerical stability decreases drastically. Under-relaxation factors are set to 0.5 for pressure, momentum and volume fraction equations and to 0.7 for turbulent equations. Time discretization is done by imposing CFL $<$ 1, as suggested by Guédon et al. (2017). Time step size sensitivity has been studied for different operating conditions and column size. The optimal time step size is $0.005 \mathrm{~s}$, with maximum residual values below 0.0001 for every equation and every case. Sensitivity analysis on time discretization has been carried out, but it is omitted for the sake of brevity.

Both homogeneous and heterogeneous flow regimes are studied. The homogeneous flow regime is classified into mono-disperse homogeneous flow regime and pseudo-homogeneous flow regime depending on the prevailing bubble size distributions, as stated by Guédon et al. (2017), in accordance with Fig. 2a. CFD simulations considers the bubble size as an input parameter. A constant bubble diameter is considered (mono-disperse approach), in the range of the experimental values. Experiments provide local Sauter diameters that locally vary from $5 \mathrm{~mm}$ to $8 \mathrm{~mm}$, in the case of systems with air and tap water (see Raimundo (2015) and Gemello et al. (2018) for details), as shown in the terminal velocity diagram of Clift et al. (1978) (Fig. 2b). The averaged mean Sauter diameter is about $6.5 \mathrm{~mm}$ for every operating condition and column size investigated in this study. In the case of homogeneous regime, the profile is flat with a constant value of about $6.5 \mathrm{~mm}$. In the case of heterogeneous regime, the profile has a maximum in the center of the column. The concavity grows with the su-

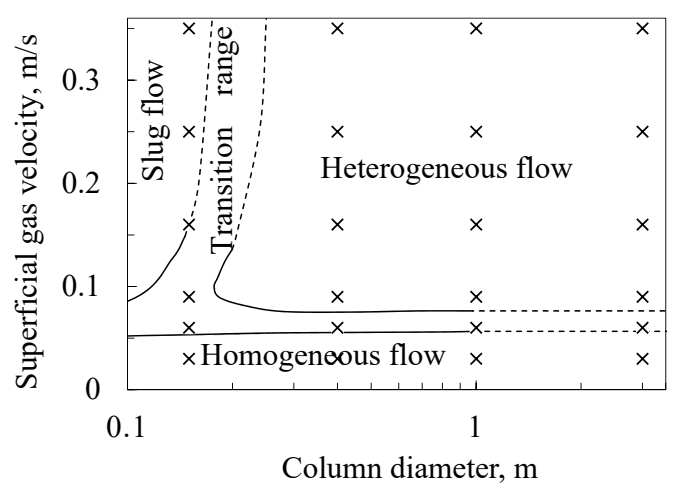

(a) Flow regime map of Shah et al. (1982) and simulated cases $(\times)$.

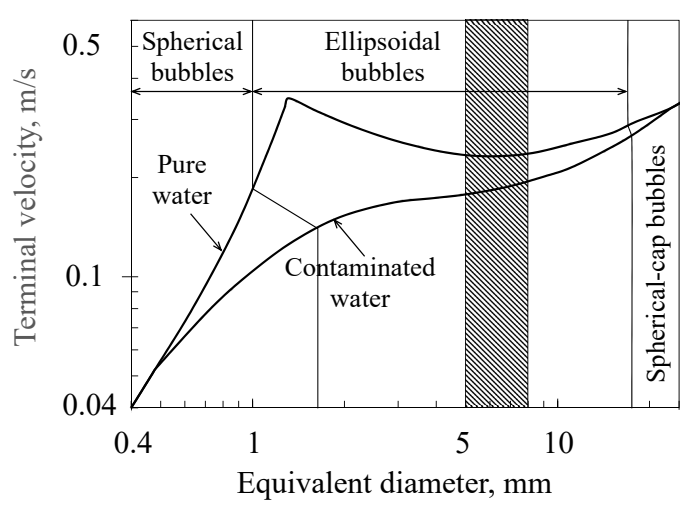

(b) Terminal velocity diagram of Clift et al. (1978).

Figure 2: Operating range of CFD simulations.

perficial gas velocity, but the time-averaged and spaceaveraged value of the bubble diameter is similar to 6.5 $\mathrm{mm}$. As a consequence, a fixed value of $6.5 \mathrm{~mm}$ is used in these CFD simulations for every operating condition.

Turbulence can be described using different approaches and in this work different two-equation models are tested: standard k- $\varepsilon$, RNG k- $\varepsilon$, realizable k- $\varepsilon$ and k$\omega$. In this article, for the sake of brevity, only the hydrodynamic results obtained using the RNG k- $\varepsilon$ model are reported. Concerning the mixing time, that strongly depends on the turbulence properties, the results obtained with the RNG k- $\varepsilon$ and the k- $\omega$ models are reported with a view to comparing them.

\subsection{Geometry and meshes}

The columns are considered cylinders with an initial height of the liquid equal to four diameters. In order to ensure that the column can be used with a maximum gas volume fraction up to $50 \%$, the total height of the column should be at least twice of the initial height of the liquid. Firstly, the column with a diameter of $0.4 \mathrm{~m}$ 
is simulated. This column has an initial height of the liquid equal to $1.6 \mathrm{~m}$ and a total height of $3.6 \mathrm{~m}$ (Fig. $3 a)$. Initially only liquid is present below the interface. Subsequently simulations start using the previous one as the initial condition in order to be able to carry out the simulations faster and minimize downtime.

Experimentally the gas is injected through different holes at the bottom of the column. The perforated sparger used consists in 92 holes of $2 \mathrm{~mm}$ of diameter for the $0.4 \mathrm{~m}$ diameter column. Given the high number of holes it has been chosen to approximate the real sparger by a homogeneous porous plate, as it is customary. Fortunately, as observed by Gemello et al. (2018), these gas distributors ensure a near-homogeneous gas distribution for every column (Raimundo, 2015). The inlet zone conditions have effects in the entire column in case of homogeneous regime, while in case of heterogeneous regime the effects of the inlet zone conditions are almost negligible, as stated by Gemello et al. (2018). The main objective of this work is to be able to carry out industrial simulations where it is not possible to simulate the real sparger. It is preferable to use, in CFD simulations, a homogeneous sparger where the gas enters the domain already mixed with some liquid. The volume fraction of the disperse phase in the bottom of the column is generally chosen to be around 0.5 (Li et al., 2009). A turbulent intensity of $5 \%$ and a turbulent viscosity ratio equal to 10 are imposed as inlet boundary conditions. This choice allows to avoid turbulent instabilities close to the bottom. The more external ring of the bottom (with a thickness of $0.01 \mathrm{~m}$ for the column $\phi 0.4 \mathrm{~m}$ ) (white background in Fig. 3b) is considered as a wall, while the gas enters the column in the remaining part of the bottom (grey background in Fig. $3 b)$. The external ring avoids convergence problems and it induces liquid recirculation, observed in experiments. The outlet zone in the top of the column is considered a pressure outlet with a gauge pressure of $0 \mathrm{~Pa}$. It has a complete backflow of gas. The backflow turbulent intensity is equal to $0.001 \%$ and the backflow turbulent length scale is equal to $0.4 \mathrm{~m}$.

Starting from the column $\phi 0.4 \mathrm{~m}$, different numerical grids are tested:

- A tetrahedral irregular mesh leads to completely wrong results and the column lost water, i.e. the total amount of water present within the column decreases continuously with time.

- A Coopering algorithm in Gambit allows to obtain better results. In this work, the mesh obtained with the Coopering algorithm is called "cooper mesh". The cooper mesh is a hexahedral mesh

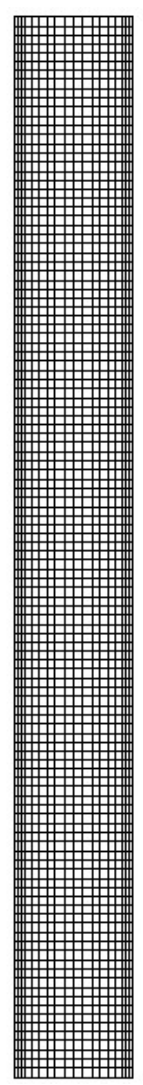

(a) Axial section.

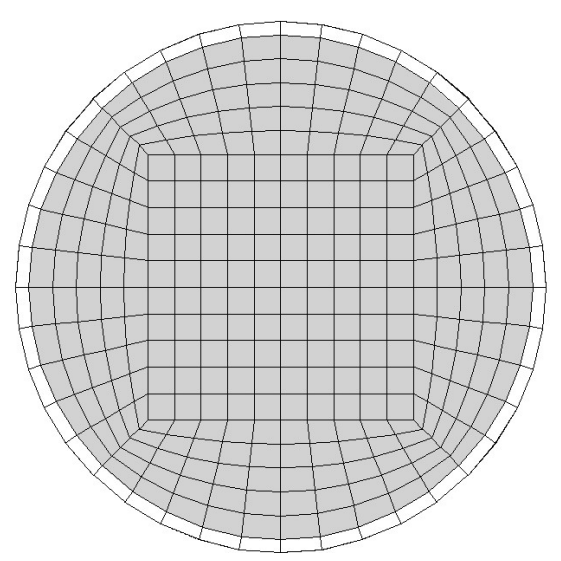

(b) Bottom and sparger.

Figure 3: Schematic representation of the bubble column and its mesh. 
where initially an unstructured tetragonal 2D mesh is mapped at the bottom and it is then extruded along the column. By using this mesh, the results are acceptable, but the computational cost is high.

- A more regular mesh with a smaller cells count can be created: a cooper mesh with a rhomboidal bottom. An analysis on the sensibility of the results on the cell size is necessary. This mesh is reported in Fig. 3b.

Sensitivity analysis on mesh size is carried out. Different rhomboidal cooper meshes are tested, varying the mesh size and subsequently the number of cells. Starting with a very fine mesh, of about 500,000 cells the number of cells is gradually reduced. Until a rhomboidal cooper mesh with 40,000 cells, the hydrodynamic results do not depend on the mesh choice. The differences between the 500,000 cells and 40,000 cells meshes are above $10 \%$ for every hydrodynamic property. Considering a mesh coarser than 40,000 cells, the results start to depend on the mesh choice. If the mesh resolution is too low, the accuracy required to consider the main transient phenomena is not respected. A rhomboidal cooper mesh with 40,000 cells gives satisfactory results and it allows to maintain acceptable computational time, even for larger domain, by simply scalingup the mesh. This mesh is reported in Fig. 3. This mesh allows to consider the transient phenomena. Grid independent test on the gas hold-up, using the new swarm factor proposed in chapter 4.1, confirms that the 40,000 cells gives mesh-independent results for the column $\phi$ $0.4 \mathrm{~m}$, as detailed in Table 2. Other grid independent tests confirm that this mesh is also suitable for the scaleup in the studied cases.

\begin{tabular}{ccccccc}
\hline vsg, m/s & 0.03 & 0.06 & 0.09 & 0.16 & 0.25 & 0.35 \\
\hline Experimental & 12.8 & 20.0 & 20.8 & 26.3 & 32.2 & 37.3 \\
500000 cells & 12.5 & 17.4 & 19.0 & 24.2 & 30.1 & 33.8 \\
150000 cells & 12.4 & 17.3 & 19.0 & 24.1 & 29.8 & 34.1 \\
40000 cells & 12.6 & 17.3 & 18.9 & 24.1 & 29.6 & 34.1 \\
10000 cells & 12.1 & 16.9 & 22.0 & 24.8 & 26.8 & 29.9 \\
\hline
\end{tabular}

Table 2: Grid independent test: gas hold-up using the new swarm factor for the column $\phi 0.4 \mathrm{~m}$ with different cooper meshes.

Using the rhomboidal cooper mesh with 40,000 cells, $y+$ ranges from 30 to 500. CFD simulations should typically have a $y+$ value that ranges from 30 to 300 . It is important if the aim is to solve the flow along a wall accurately, which will affect pressure drop, wall shear force, wall lubrication force. In a large volume, $\mathrm{y}+$ is not the most important parameter. In CFD simulations carried out in this work, phase interaction models are more important. Near wall treatments and y+ are negligible. Standard wall functions are used.

The Wilkinson et al. (1992) scale-up criteria must be respected (Besagni et al., 2018). These criteria are almost satisfied:

- "The diameter of the bubble column ought to be larger than $0.15 \mathrm{~m}$ ". This criterion is satisfied for the 3 bigger columns ( $\phi 0.4 \mathrm{~m}, \phi 1 \mathrm{~m}$ and $\phi 3 \mathrm{~m})$. These columns should provide almost the same hydrodynamic results. The $\phi 0.15 \mathrm{~m}$ column is the limit of the criterion.

- "The aspect ratio must be larger than 5". Concerning this point, some authors defined the aspect ratio in terms of the column height, while other authors defines the aspect ratio in function of the initial liquid level, as proposed by Sasaki et al. (2016) and stated by Sasaki et al. (2017) and Besagni et al. (2017). The studied columns have an aspect ratio that is higher than 8 , if the total height of the column is considered and our simulations respect largely the criterion. If the initial liquid level is considered, our simulations are slightly below this criterion limit $\left(\mathrm{H}_{0} / \mathrm{D}=4\right)$. It is important to consider that under our operating conditions, the actual liquid level is about 5 or 6 diameters, due to the presence of high gas volume fractions. Forret (2003) stated that, under these operating conditions, the actual operating height of the liquid (aerated heights) ought to be at least 4 times the column diameter and this condition is satisfied.

- "The holes of gas sparger larger than 1-2 mm". This criterion is satisfied for the columns $\phi 0.4 \mathrm{~m}$, $\phi 1 \mathrm{~m}$ and $\phi 3 \mathrm{~m}$. These columns provide similar hydrodynamic results. The column $\phi 0.15 \mathrm{~m}$ has holes of $1 \mathrm{~mm}$, that is the limit of the criterion.

\section{Results and discussion}

\subsection{Drag law and swarm factor}

CFD simulations are carried out using several drag laws valid also for oblate bubbles. The best results are always obtained with the drag laws of Tomiyama (1998) and Zhang et al. (2006). Only the results with the drag law of Tomiyama (1998) are reported in this article. CFD simulations with this drag law result always in very high gas volume fractions, for any superficial gas velocity investigated, except for $0.03 \mathrm{~m} / \mathrm{s}$ (Fig. 4). The inaccuracy of the model is large, with the liquid reaching the top of the domain already for a superficial gas 
velocity equal to $0.16 \mathrm{~m} / \mathrm{s}$. It is useless to analyze the radial profile for these simulations, as the global results are completely wrong. The drag coefficient is always too high: it is necessary to consider a swarm factor. Every simulation performed without swarm factors leads to an overestimation of the gas hold-up under the heterogenous regime.

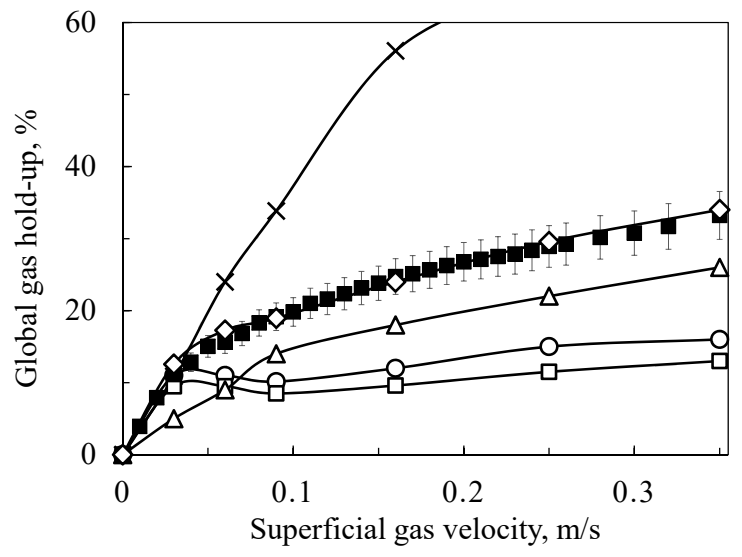

Figure 4: Comparison between experimental ( $\boldsymbol{\square})$ and CFD gas holdup for different superfical gas velocities in the column $\phi 0.4 \mathrm{~m}$ using the drag law of Tomiyama (1998) without swarm factor $(\times)$, considering the swarm factor of Simonnet et al. (2008) ( $\bigcirc)$, the swarm factor of McClure et al. (2014) ( $\square$ ), the swarm factor of McClure et al. (2017b) $(\triangle)$ and the new swarm factor $(\diamond)$.

Every swarm factor that increases the drag coefficient cannot be used. Under heterogeneous regime, the swarm factor must reduce the final drag coefficient by decreasing the drag force for high gas volume fractions, as pointed out by (McClure et al., 2017b). The swarm factor of Simonnet et al. (2008) (Equation 4) has this characteristic. Therefore, this swarm factor is considered and coupled with the drag law of Tomiyama (1998). As it can be observed in Fig. 4, the gas holdup predicted by implementing the swarm factor is lower than the experimental one. This could mean that the effect of the swarm factor of Simonnet et al. (2008) is too strong. It is also important to mention that these simulations hardly converge due to the instantaneous behavior of the gas volume fraction. As it can be observed in Fig. 5 , some big clusters of gas are created in these simulations, while the clusters are absent in the experiments. In these simulations, the bubbles cluster together, creating areas where the local gas volume fraction is equal to one and others where only the liquid is detected (Fig. $5)$. This phenomenon is supposed to be linked by the asymptotic fall of the swarm factor of Simonnet et al. (2008) in case of very high gas volume fraction. The gas volume fraction is lower that $30 \%$ in the experiments of
Simonnet et al. (2008). This swarm factor is suitable only up to $30 \%$ of gas volume fraction and normally in CFD simulations, due to local and instantaneous fluctuations, local values can be bigger than $30 \%$. Therefore, when the gas volume fraction is locally greater than 0.3 , the drag force drastically decreases, going down almost to zero and causing the formation of large unphysical bubble clusters.
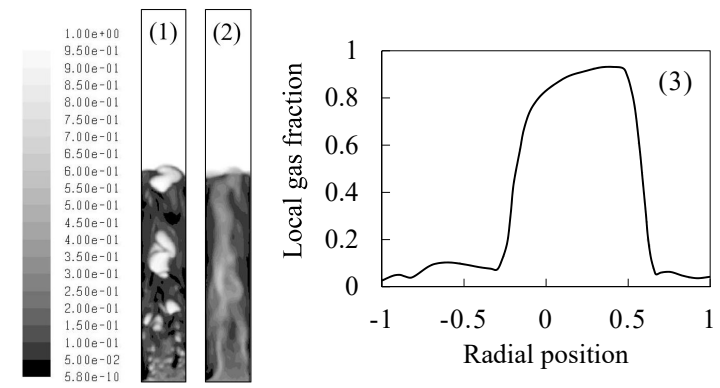

(a) Swarm factor of Simonnet et al. (2008).

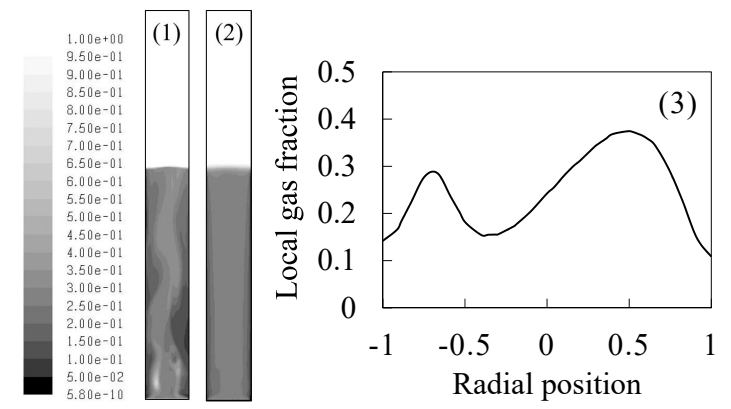

(b) New swarm factor.

Figure 5: Gas volume fraction for the column $\phi 0.4 \mathrm{~m}$ for a superficial gas velocity of $0.16 \mathrm{~m} / \mathrm{s}$ : (1) instantaneous behavior, (2) sampled behavior and (3) instantaneous radial profile at $\mathrm{H} / \mathrm{D}=2.5$.

McClure et al. (2014) proposed a corrected version of the Simonnet et al. (2008) swarm factor. The drag force effect was modeled using the Favre-averaged model proposed by Burns et al. (2004). The Grace et al. (1976) drag law for isolated bubbles was considered, in combination with their modified swarm factor, proposed in their article. Liquid phase turbulence was modeled using the $\mathrm{k}-\varepsilon$ model, considering additional source terms that take into account the bubble-induced turbulence model proposed by Pfleger and Becker (2001). McClure et al. (2014) had not the problem of the formation of large unphysical bubble clusters, but they considered the Favre-averaged drag model and bubble-induced turbulence. For high gas volume fractions, McClure et al. (2017b) criticized the Simonnet et al. (2008) swarm factor model and their modifications (i.e. McClure et al. (2014)). 
McClure et al. (2017b) proposed an alternative swarm factor, with empirical parameters (Equation 6). This swarm factor is tested in this work. The clustering is absent, but the global gas hold-up is not well-predicted for every operating condition. The authors suggest that the correlation is in agreement with the experimental data only for a high gas volume fraction.

In order to obtain a global swarm factor that fits well the experimental data for each investigated operating condition, the swarm factor of Simonnet et al. (2008) is modified, adding a minimum constant value for $h$. The new swarm factor has the same behavior by up to $30 \%$, but does not decrease down to zero at higher gas volume fractions; it has instead a constant value. Different values of $h_{\text {min }}$ are tested, resulting in the following modified swarm factor correlation:

$$
h=\max \left\{\left(1-\alpha_{g}\right)\left[\left(1-\alpha_{g}\right)^{25}+\left(4.8 \frac{\alpha_{g}}{1-\alpha_{g}}\right)^{25}\right]^{-\frac{2}{25}}, h_{\min }\right\} .
$$

The column $\phi 0.4 \mathrm{~m}$ is simulated for several superficial gas velocities with $h_{\text {min }}=0.15$ and, as it is seen in Fig. 4 , CFD results with this swarm factor are in good agreement with the experimental data. In this case, the phase segregation disappears: there are only fluctuations and small zones where the air concentration is quite bigger and some instantaneous preferential path for bubbles as it happens in real bubble columns (Fig. 5).

Since the results obtained by using the swarm factor reported in Eq. 10 are found to be in good agreement with experiments, also the other bubble columns are simulated with this parameter: $\phi 0.15 \mathrm{~m}, \phi 1 \mathrm{~m}$ and $\phi 3 \mathrm{~m}$. The column $\phi 0.4 \mathrm{~m}$ is scaled without other modifications to keep the number of cells of the mesh constant. The discrepancies are below 10\%, that corresponds roughly to the experimental error. Although a fine tuning of $h_{\min }$ is possible between 0.12 and 0.18 to fit simulations to experiments at each scale, it is finally preferred to use a constant value and to recommend keeping this value constant for scale-up at larger scale. The discrepancies between experimental data and CFD results are rather small, as reported in Fig. 6.

The discrepancies are slightly higher for the column $\phi 0.15 \mathrm{~m}$. These differences can be explained with the Wilkinson et al. (1992) scale-up criteria: this column is at the limit of the first and the third criteria, causing discrepancies between the results obtained with this column and the others.

The bubble diameter has been chosen in the range of size measured experimentally (from 5 to $8 \mathrm{~mm}$ ). The terminal velocities are poorly affected by the bubble size in this range in the case of contaminated bubbles, has reported in Fig. 2b. Preliminary terminal velocity cal-

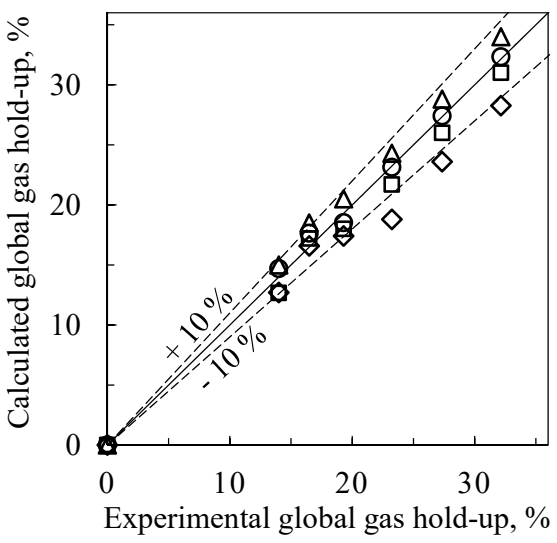

Figure 6: Scale-up effect on the gas hold-up using the Tomiyama (1998) drag law and the new swarm factor $\left(h_{\min }=0.15\right)$. Parity graph for the gas hold-up between experimental (Raimundo, 2015) and CFD data for different columns: $\phi 0.15 \mathrm{~m}(\diamond), \phi 0.4 \mathrm{~m}(\square), \phi 1 \mathrm{~m}(\bigcirc)$ and $\phi 3 \mathrm{~m}(\triangle)$.

culations based on Tomiyama (1998) and Zhang et al. (2006) drag laws are coherent with this. Non-reported comparison of CFD simulations operated at different gas velocity have also been performed to state the negligible effect of the bubble size in this range. As a consequence, in this work every simulation is performed considering a constant bubble size of $6.5 \mathrm{~mm}$.

Fig. 7 reports comparison of radial profile of gas volume fraction for the column $\phi 0.4 \mathrm{~m}$ and the column $\phi 1 \mathrm{~m}$. It allows to recognize the flow regime. The radial profile is almost flat in case of homogeneous regime $(0.03 \mathrm{~m} / \mathrm{s})$ and it is parabolic in case of heterogeneous regime $(0.16 \mathrm{~m} / \mathrm{s})$.

Another important parameter in bubble columns is the liquid velocity at the center of the column, as it strongly influences the mixing time and it is a key parameter in case of bioreactors, where high velocities and shear stress can damage the microorganisms of the biomass, lowering the yield of the bioprocess. The liquid velocity in the center is compared with the experimental data of Forret (2003) and the correlation of Miyauchi and Shyu (1970), as presented in Fig. 8. The liquid velocity in the center is correctly predicted using the new swarm factor with $h_{\text {min }}=0.15$. The radial profiles of gas velocity and liquid velocity are correctly predicted: gas and liquid velocities have a quadratic dependence on the radial position and this dependence is stronger in case of higher superficial gas velocity. For the sake of brevity, in Fig. 9, only the liquid velocity radial profile for a superficial gas velocity equal to 0.03 $\mathrm{m} / \mathrm{s}$ and $0.16 \mathrm{~m} / \mathrm{s}$ is reported. By using the new swarm factor, CFD and experimental liquid velocity profiles 


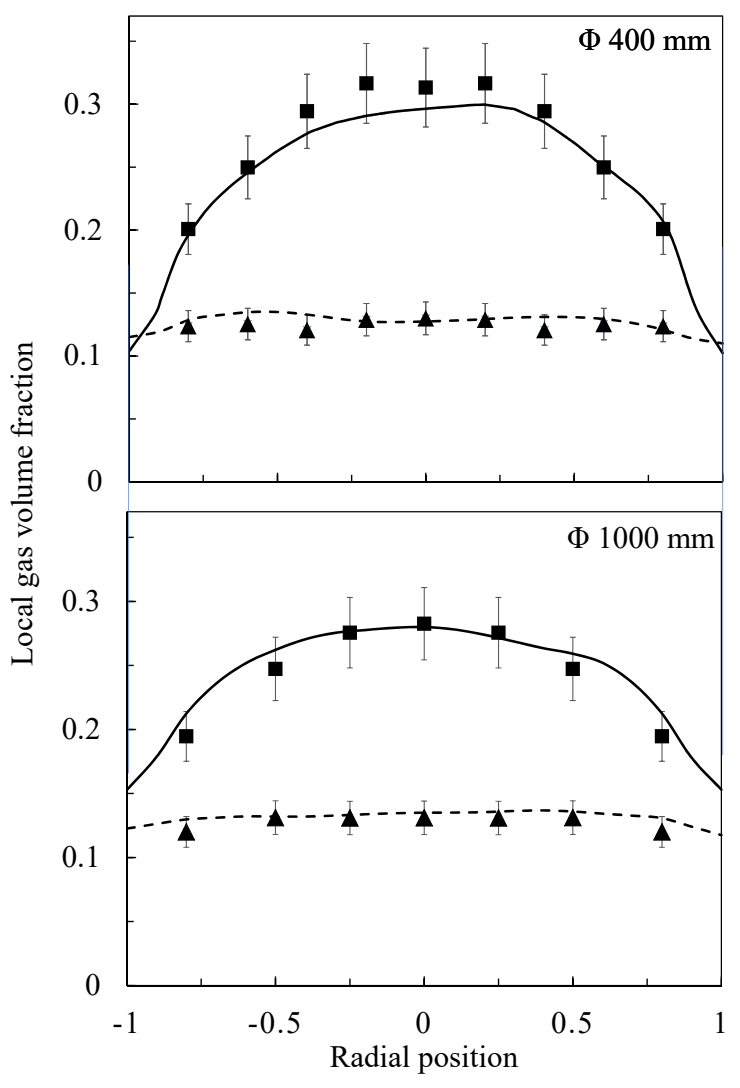

Figure 7: Experimental versus CFD sampled radial profiles at $\mathrm{H} / \mathrm{D}=2.5$ of the gas volume fraction using the new swarm factor for the column $\phi 0.4 \mathrm{~m}$ and the column $\phi 1 \mathrm{~m}$ for a superficial gas velocity equal to $0.03 \mathrm{~m} / \mathrm{s}$ (experimental ( $\boldsymbol{\Delta})$ vs CFD (dashed line)) (homogeneous regime) and $0.16 \mathrm{~m} / \mathrm{s}$ (experimental (ם) vs CFD (solid line)) (heterogeneous regime).

are almost identical for every operating condition investigated in this study. It can be concluded that this new formulation of the swarm factor, coupled with the drag law of Tomiyama (1998), leads to a correct hydrodynamic description of the system.

Some simulations were carried out considering also the lift force, but, in case of heterogeneous regime, the simulation became not stable, requiring shorter time step and huge computational time, without furnishing real advantages. Virtual mass is tested, but it leads to unstable simulations. Beyond the use of lift force under heterogeneous regime, which is still an open question, the physical meaning of the suggested swarm factor is not well understood. There is no understanding of the strong reduction of the drag force at high gas fraction. One possible explanation may be the very complex interactions between bubbles and large turbulent eddies. As a consequence, the resulting apparent drag

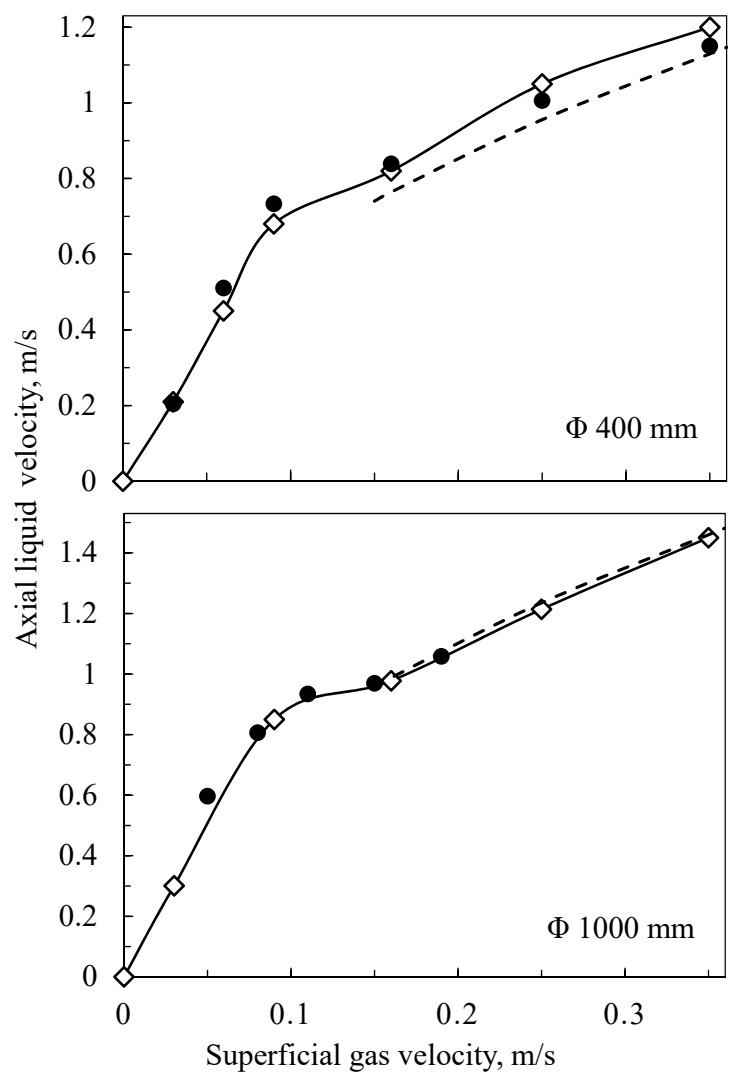

Figure 8: Liquid velocity in the center at $\mathrm{H} / \mathrm{D}=3.75$ for the column $\phi$ $0.4 \mathrm{~m}$ and the column $\phi 1 \mathrm{~m}$ : experimental data of Forret (2003) (•) versus CFD data obtained using the new swarm factor $(\diamond$ and solid line) versus correlation of Miyauchi and Shyu (1970) (dashed line).

law can be considered as an integrated interfacial exchange term, which follows the formalism of a drag force but including probably other local bubble-liquid forces. Standard k- $\varepsilon$, realizable k- $\varepsilon$ and RNG k- $\varepsilon$ models are studied. Standard k- $\varepsilon$ and realizable $\mathrm{k}-\varepsilon$ models give numerical errors for higher superficial gas velocities. Standard k- $\varepsilon$ model slightly overestimates the gas fraction in the center on the column (Fig. 10a) and underestimates the liquid velocity in the center on the column (Fig. 10b) under the heterogeneous regime. Realizable $\mathrm{k}-\varepsilon$ model provides a correct gas volume fraction profile, while the liquid velocity in the center on the column is underestimated, as shown in Fig. 10. RNG k- $\varepsilon$ model provides better and more stable results. The k- $\omega$ model is more commonly used for external flows or for turbulent boundary layer resolution needs. The k-omega model has been tested in a comparative view. The radial profiles of local gas volume fraction and axial liquid velocity obtained with the k- $\omega$ model are very similar to those obtained by using the RNG k- $\varepsilon$ model (Fig. 10). 


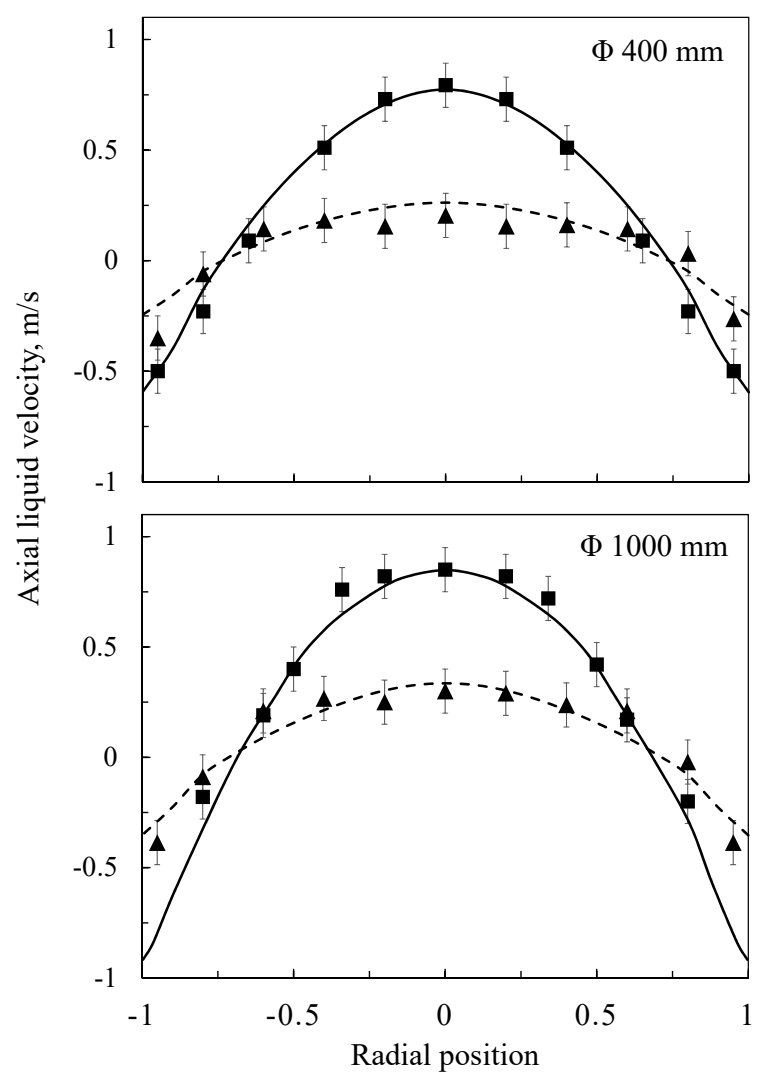

Figure 9: Experimental versus CFD sampled radial profiles of the liquid velocity using the new swarm factor for the column $\phi 0.4 \mathrm{~m}$ and the column $\phi 1 \mathrm{~m}$ for a superficial gas velocity equal to $0.03 \mathrm{~m} / \mathrm{s}$ (experimental ( $\boldsymbol{\Delta})$ vs CFD (dashed line)) (homogeneous regime) and 0.16 $\mathrm{m} / \mathrm{s}$ (experimental (ם) vs CFD (solid line)) (heterogeneous regime) at $\mathrm{H} / \mathrm{D}=3.75$.

\subsection{Mixing time}

Different turbulence models are tested. In this article, for the sake of brevity, only the mixing time results obtained using the RNG k- $\varepsilon$ and the k- $\omega$ models are reported. They provide the best agreement with the experimental data concerning the hydrodynamics, as explained above.

The tracer response data is available only for the column $\phi 1 \mathrm{~m}$ (Forret, 2003). The diffusion coefficient is defined in three different ways for each simulation: by considering only the molecular diffusivity, then by adding the shear-induced turbulence (SIT) and, eventually, also the bubble-induced turbulence (BIT). In Fig. 11 , the simulated concentration profile is compared to the experimental data.

Simulation curves are obtained by averaging the scalar concentration over the column section at the same height of the experimental samplings. Besides the cases

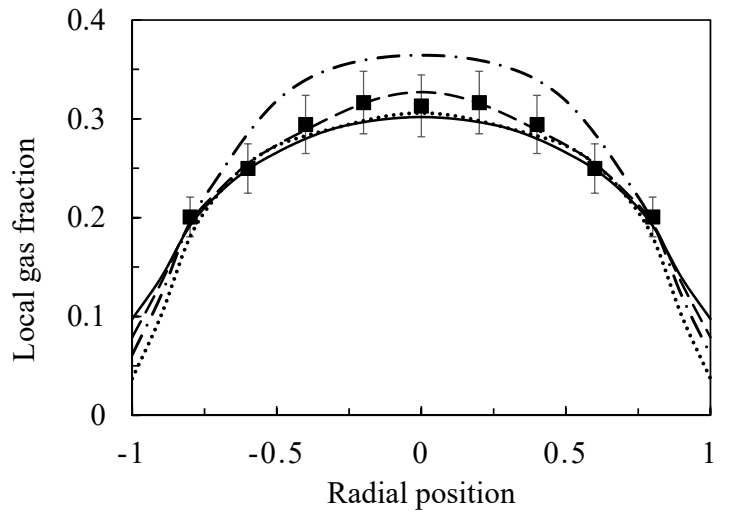

(a) Gas volume fraction at $\mathrm{H} / \mathrm{D}=2.5$.

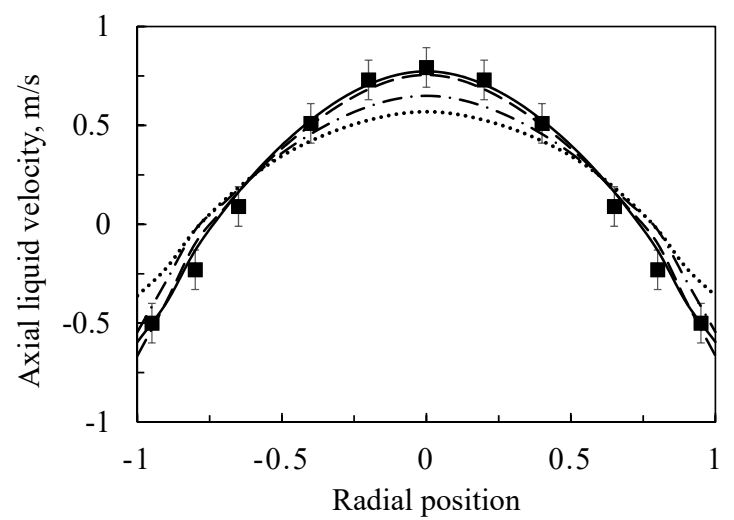

(b) Axial liquid velocity at $\mathrm{H} / \mathrm{D}=3.75$.

Figure 10: Turbulence models comparison of the hydrodynamic radial profiles for the column $\phi 0.4 \mathrm{~m}$ for a superficial gas velocity of 0.16 $\mathrm{m} / \mathrm{s}$ : standard k- $\varepsilon$ (dash dot line), realizable k- $\varepsilon$ (dotted line), RNG $\mathrm{k}-\varepsilon$ (solid line) and k- $\omega$ (dashed line).

simulated with only the molecular diffusivity term in the transport equation, the numerical profiles are in good agreement with the experimental values. The RNG k- $\varepsilon$, in particular, gives a very accurate profile of the concentration over time. For both the turbulence models it can be immediately noticed that the BIT term does not have great impact on the results and on the local profiles at this scale.

In Table 3, mixing times calculated with RNG k- $\varepsilon$ simulations are listed. The results confirm that adding BIT does not lead to great differences, except for the column $\phi 0.4 \mathrm{~m}$ (Fig. 12): when the superficial gas velocity is less than $0.16 \mathrm{~m} / \mathrm{s}$, a difference of about $10 \%$ is encountered. The contribution of the bubble should be considered for small-scale systems, in agreement with the results presented in Alméras et al. (2015).

McClure et al. (2014) obtained satisfactory results for a small column of $0.19 \mathrm{~m}$ equipped with a square perforated sparger by using the BIT model of Pfleger 


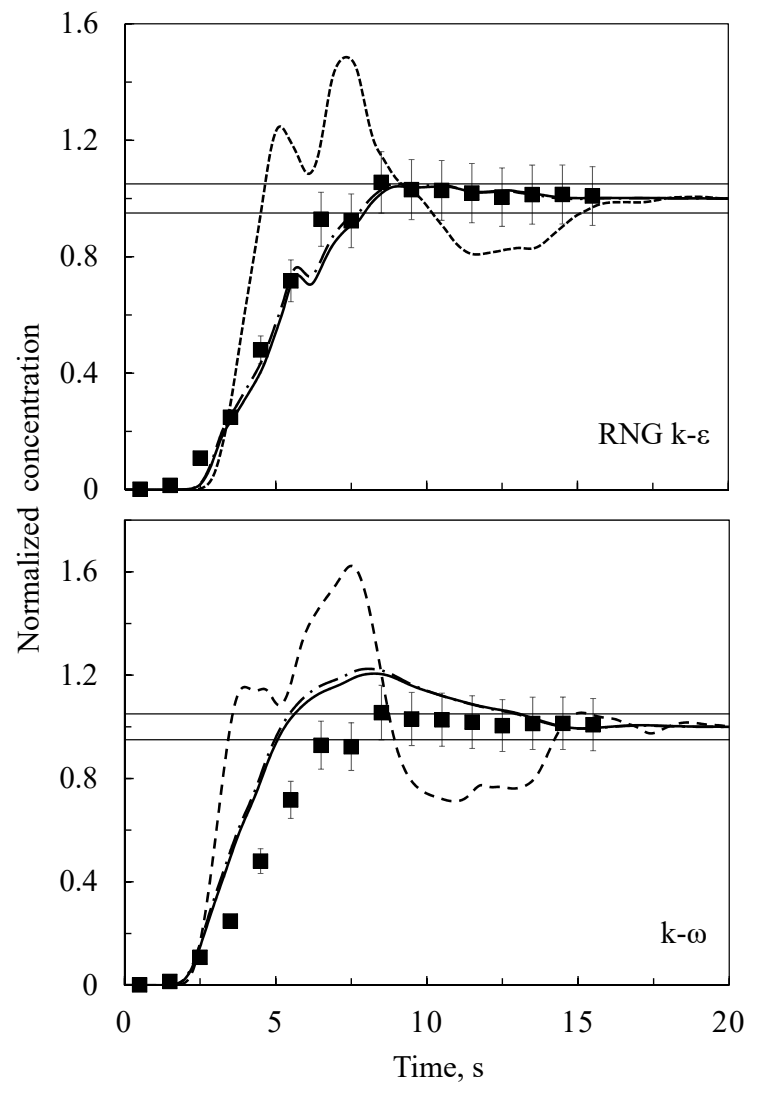

Figure 11: Local normalized concentration for the column $\phi 1 \mathrm{~m}$ for a superficial gas velocity of $0.15 \mathrm{~m} / \mathrm{s}$. Comparison of the experimental data of Forret (2003) (ם) with the CFD simulations using molecular diffusivity only (dashed line), SIT (dash dot line) and BIT + SIT (solid line).

\begin{tabular}{ccccccc}
\hline$v_{s g}, \mathrm{~m} / \mathrm{s}$ & \multicolumn{2}{c}{0.09} & \multicolumn{2}{c}{0.16} & \multicolumn{2}{c}{0.25} \\
\hline BIT & yes & no & yes & no & yes & no \\
\hline$\phi 0.4 \mathrm{~m}$ & 6.70 & 7.70 & 4.70 & 5.50 & 3.40 & 3.60 \\
$\phi 1 \mathrm{~m}$ & 12.30 & 12.40 & 10.20 & 11.10 & 5.38 & 5.35 \\
$\phi 3 \mathrm{~m}$ & 36.70 & 37.75 & 31.08 & 31.22 & 23.20 & 23.33 \\
\hline
\end{tabular}

Table 3: Mixing time in seconds using RNG k- $\varepsilon$ and diffusivity model of Alméras et al. (2016).

and Becker (2001), which permitted to fit the simulated gas volume fraction profile with the experimental data. The results presented in this paper, show that the hydrodynamics is correctly determined without corrective terms to include BIT contribution in the $\mathrm{k}$ and $\varepsilon$ transport equations. The reasons of these differences are not clear. McClure et al. (2014) realized their simulations with ANSYS CFX, while in this paper the simulations are carried out with ANSYS Fluent. Fletcher et al. (2017) proved that with identical closure models

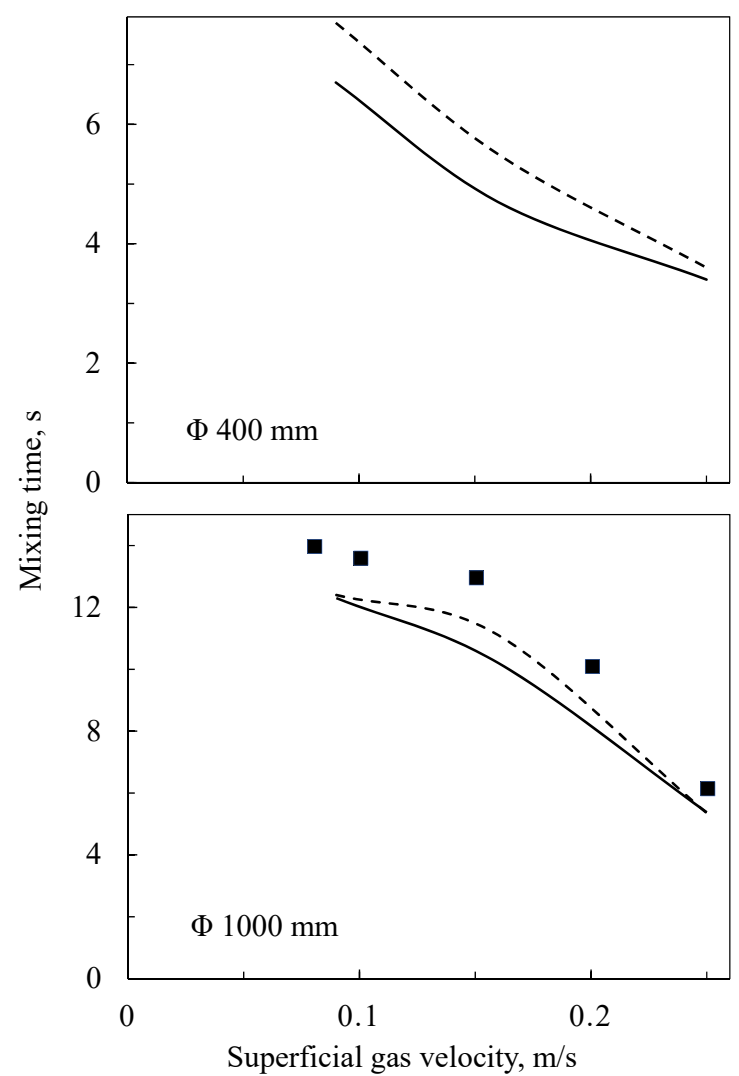

Figure 12: Mixing time as a function of the gas velocity, computed by using the RNG k- $\varepsilon$ model coupled with SIT (dashed line) and BIT + SIT (solid line). Comparison with the experimental data of Forret (2003) (ם).

the codes give virtually identical results. A possible explanation may be the difference of geometry (column diameter and sparger) and operating conditions. The new drag law allows to obtain CFD results in good agreement with the experimental data. The phase segregation disappears: small zones where the air concentration is higher and instantaneous preferential path for bubbles simulate the formation of experimental instantaneous gas macro-structure, as shown in Fig. 5. This behavior influences the mixing time. More detailed studies are necessary to fully understand the BIT effects. It can be an important perspective in this field.

Furthermore, mixing time is strongly influenced by the column diameter and by the superficial gas velocity, as it can be noticed in Fig. 13, where mixing times are presented as a function of the column size and the superficial gas velocity. The values refer to simulations with both $\mathrm{k}-\omega$ and RNG k- $\varepsilon$ and the Alméras et al. (2015) model for the turbulent diffusivity.

At higher gas velocities, the mixing time is shorter. 


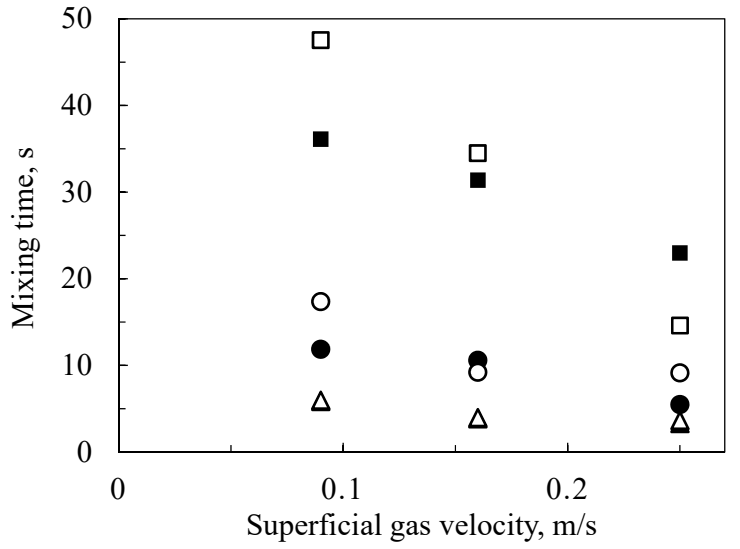

Figure 13: Column diameter and superficial gas velocity effects on the mixing time. Comparison between two different turbulence models: RNG k- $\varepsilon(\Delta \phi 0.4 \mathrm{~m}, \boldsymbol{\bullet} 1 \mathrm{~m}$ and $\phi 3 \mathrm{~m})$ and $\mathrm{k}-\omega(\triangle \phi 0.4 \mathrm{~m}, \bigcirc \phi$ $1 \mathrm{~m}$ and $\square \phi 3 \mathrm{~m})$.

Concerning the choice of the turbulence model, it can also be seen that values differ a little for the smallest column, while bigger discrepancies are encountered as the column size increases.

The turbulent viscosity is an important parameter to model the transport of the scalar, as it appears directly in the diffusion coefficient. A comparison between the simulated viscosity and several correlations shows that the CFD values fall into the range of the correlation proposed by Kawase and Moo-Young (1989), while stronger discrepancies occur with the correlations of Miyauchi and Shyu (1970) and Burns and Rice (1997) (Fig. 14). This result is in agreement with Guédon et al. (2017)

Fig. 14 allows to compare the turbulent kinematic viscosity in case of RNG k- $\varepsilon$ model and $\mathrm{k}-\omega$ model. It is interesting that, even if the k- $\omega$ model gives a turbulent viscosity that is almost twice that from the RNG k$\varepsilon$, mixing time computed with the latter is shorter. This apparent contradiction could be explained considering that in addition to the diffusive phenomena, there is still the convective transport with the mean flow field. Considering only the molecular diffusion of the scalar leads to longer mixing time. Moreover, for the $\mathrm{k}-\omega$ this increase is more significant, so it can be deduced that, for the RNG k- $\varepsilon$ model, the macro recirculation is more intense, leading to a quicker spread of the tracer inside the column, even if the turbulent dispersion is stronger with the k- $\omega$ model.
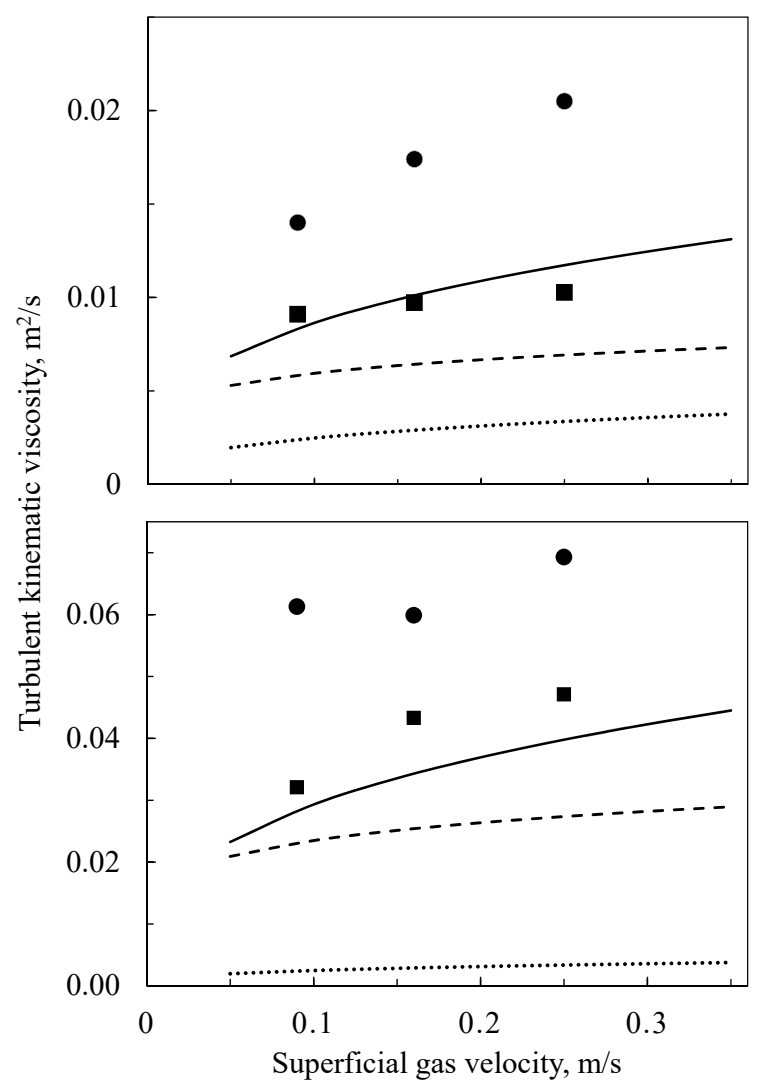

Figure 14: Turbulent kinematic viscosity versus the superficial gas velocity: RNG k- $\varepsilon(\boldsymbol{\square})$ versus k- $\omega(\bullet)$. Comparison with correlations: Burns and Rice (1997) (dotted line), Kawase and Moo-Young (1989) (solid line) and Miyauchi and Shyu (1970) (dashed line).

\section{Conclusions}

For bubble columns under the heterogeneous regime, the drag force is the main interfacial force. A drag law that is suitable also for oblate bubbles, as Tomiyama (1998), is used. This should be modified considering a swarm factor, that decreases the drag force for high gas volume fraction. With the swarm factor of Simonnet et al. (2008) the simulations hardly converge and the computed gas hold-up is lower than the experimental one. The instantaneous behavior is completely incorrect, with bubbles that create unphysical big clusters. This swarm factor is not appropriate for gas volume fraction higher than $30 \%$.

By modifying the swarm factor of Simonnet et al. (2008) by introducing a minimum value (Equation 10), the CFD simulations provide results very similar to the experimental data and the gas segregation problems are avoided. The radial profiles of gas volume fraction, gas velocity and liquid velocity are similar to experiments. 
For the biggest columns, the discrepancy between the experimental data and the CFD results is very small: this swarm factor can be assumed appropriate for industrial scale-up. It is recommended to use a constant value of $h_{\min }=0.15$. This value is valid for every bubble column with a diameter greater than or equal to $0.4 \mathrm{~m}$.

To simulate the dispersion of a scalar, an extra diffusion coefficient due to bubble-induced turbulence (BIT), as presented by Alméras et al. (2015) is considered. The RNG k- $\varepsilon$ turbulence model seems to predict the scalar mixing satisfactorily, with a local response close to the experimental one. The predicted mixing time is higher when only the molecular diffusion is used to model diffusivity in the scalar transport equation and the BIT diffusivity is negligible in most of the cases analyzed. This shows the dominant contribution of the Shear Induced Turbulence (SIT) in the mixing process. For the smallest column, the diffusion caused by BIT has a significant effect on scalar mixing (about 15\%), so the contribution of the bubbles wakes to the mixing should be implemented in the simulation of bubble columns with a diameter of $0.4 \mathrm{~m}$ and smaller, for which the diffusive model of Alméras et al. (2015) had been shown to improve the numerical results.

\section{Perspectives}

These results allow to correctly predict the hydrodynamics of bubble columns under the heterogeneous regime, in the case of fixed size of the bubbles. These results should be coupled with a Population Balance Model (PBM), in order to predict the bubble size distribution, required in turn to estimate the interfacial area and the local heat and mass transfer rate. Bubble coalescence and breakage phenomena must also be studied. A multi-scale approach allows to couple CFD simulations, at the macroscopic fluid dynamics scale, and PBM, at the population dynamics scale.

Secondary interfacial forces (i.e. lift force and turbulent dispersion force), near wall treatments and different boundary conditions could be considered and studied more in details. An interesting perspective could be to carry out CFD simulations using LES turbulence modeling, in order to draw more comprehensive conclusions. A more detailed study on the effects of the BIT model proposed by Pfleger and Becker (2001) could be an important perspective. Future experiments may collect more data concerning the mixing time for the $0.4 \mathrm{~m}$ column and for the other columns.

\section{References}

Alméras, E., Plais, C., Euzenat, F., Risso, F., Roig, V. and Augier, F. (2016), 'Scalar mixing in bubbly flows: Experimental investigation and diffusivity modelling', Chemical Engineering Science 140, 114-122.

Alméras, E., Risso, F., Roig, V., Cazin, S., Plais, C. and Augier, F. (2015), 'Mixing by bubble-induced turbulence', Journal of Fluid Mechanics 776, 458-474.

Besagni, G., Di Pasquali, A., Gallazzini, L., Gottardi, E., Colombo, L. P. M. and Inzoli, F. (2017), 'The effect of aspect ratio in countercurrent gas-liquid bubble columns: Experimental results and gas holdup correlations', International Journal of Multiphase Flow 94, 53-78.

Besagni, G., Gallazzini, L. and Inzoli, F. (2018), 'On the scale-up criteria for bubble columns', Petroleum .

Boussinesq, J. (1897), Théorie de l'écoulement tourbillonnant et tumultueux des liquides dans les lits rectilignes a grande section, Gauthier-Villars et fils.

Bridge, A. G., Lapidus, L. and Elgin, J. C. (1964), 'The mechanics of vertical gas-liquid fluidized system i: Countercurrent flow', American Institute of Chemical Engineering Journal 10(6), 819-826.

Burns, A. D., Frank, T., Hamill, I. and Shi, J. M. (2004), The favre averaged drag model for turbulent dispersion in eulerian multi-phase flows, in '5th International Conference on Multiphase Flow.', Yokohama, Japan.

Burns, L. F. and Rice, R. G. (1997), 'Circulation in bubble columns', American Institute of Chemical Engineering Journal 43(6), 13901402.

Chaumat, H., Billet, A. and Delmas, H. (2007), 'Hydrodynamics and mass transfer in bubble column: Influence of liquid phase surface tension', Chemical Engineering Science 62, 7378-7390.

Clift, R., Grace, J. and Weber, M. (1978), Bubbles, Drops, and Particles, Academic Press.

Ekambara, K., Dhotre, M. T. and Joshi, J. B. (2005), 'CFD simulations of bubble column reactors: 1D, 2D and 3D approach', Chemical Engineering Science 60(23), 6733-6746.

Fletcher, D. F., McClure, D. D., Kavanagh, J. M. and Barton, G. W. (2017), 'CFD simulation of industrial bubble columns: Numerical challenges and model validation successes', Applied Mathematical Modelling 44(Supplement C), 25-42.

Forret, A. (2003), Hydrodynamics scale-up of slurry bubble columns, $\mathrm{PhD}$ thesis, Université Claude Bernard Lyon 1-IFPEN, Lyon.

Gemello, L., Plais, C., Augier, F., Cloupet, A. and Marchisio, D. (2018), 'Hydrodynamics and bubble size in bubble columns: Effects of contaminants and spargers', Chemical Engineering Science 184, 93-102.

Grace, J., Wairegi, T. and Nguyen, T. H. (1976), 'Shapes and velocities of single drops and bubbles moving freely through immiscible liquids', 54, 167-173.

Guédon, G. R., Besagni, G. and Inzoli, F. (2017), 'Prediction of gasliquid flow in an annular gap bubble column using a bi-dispersed eulerian model', Chemical Engineering Science 161, 138-150.

Hlawitschka, M., Kovts, P., Zhringer, K. and Bart, H.-J. (2017), 'Simulation and experimental validation of reactive bubble column reactors', Chemical Engineering Science 170(Supplement C), 306319.

Ishii, M. and Zuber, N. (1979), 'Drag coefficient and relative velocity in bubbly, droplet or particulate flows', American Institute of Chemical Engineering Journal 25(5), 843-855.

Jakobsen, H. A., Lindborg, H. and Dorao, C. A. (2005), 'Modeling of bubble column reactors: progress and limitations', Industrial $\mathcal{E}$ Engineering Chemistry Research 44(14), 5107-5151.

Joshi, J. (2001), 'Computational flow modelling and design of bubble 
column reactors', Chemical Engineering Science 56(21), 58935933.

Kawase, Y. and Moo-Young, M. (1989), 'Turbulence intensity in bubble columns', The Chemical Engineering Journal 40(1), 55-58.

Li, G., Yang, X. and Dai, G. (2009), 'CFD simulation of effects of the configuration of gas distributors on gas-liquid flow and mixing in a bubble column', Chemical Engineering Science 64(24), 51045116.

McClure, D. D., Dolton, T. P., Barton, G. W., Fletcher, D. F. and Kavanagh, J. M. (2017a), 'Hydrodynamics and mixing in airlift contactors: Experimental work and CFD modelling', Chemical Engineering Research and Design 127(Supplement C), 154-169.

McClure, D. D., Kavanagh, J. M., Fletcher, D. F. and Barton, G. W. (2013), 'Development of a CFD model of bubble column bioreactors: Part one - A detailed experimental study', Chemical Engineering $\mathcal{E}$ Technology 36(12), 2065-2070.

McClure, D. D., Kavanagh, J. M., Fletcher, D. F. and Barton, G. W. (2017b), 'Experimental investigation into the drag volume fraction correction term for gas-liquid bubbly flows', Chemical Engineering Science 170, 91-97.

McClure, D. D., Norris, H., Kavanagh, J. M., Fletcher, D. F. and Barton, G. W. (2014), 'Validation of a computationally efficient computational fluid dynamics (CFD) model for industrial bubble column bioreactors', Industrial $\mathcal{E}$ Engineering Chemistry Research 53(37), 14526-14543.

McClure, D. D., Wang, C., Kavanagh, J. M., Fletcher, D. F. and Barton, G. W. (2016), 'Experimental investigation into the impact of sparger design on bubble columns at high superficial velocities', Chemical Engineering Research and Design 106, 205-213.

Miyauchi, T. and Shyu, C.-N. (1970), 'Flow of fluid in gas bubble columns', Kagaku Kogaku 34(9), 958-964.

Paul, E., Atiemo-Obeng, V. and Kresta, S. (2004), Handbook of Industrial Mixing: Science and Practice, Wiley.

Pfleger, D. and Becker, S. (2001), 'Modeling and simulation of the dynamic flow behavior in a bubble column', Chemical Engineering Science 56, 1737-1747.

Raimundo, P. M. (2015), Analysis and modelization of local hydrodynamics in bubble columns, $\mathrm{PhD}$ thesis, Université Grenoble Alpes.

Raimundo, P. M., Cartellier, A., Beneventi, D., Forret, A. and Augier, F. (2016), 'A new technique for in-situ measurements of bubble characteristics in bubble columns operated in the heterogeneous regime', Chemical Engineering Science 155, 504-523.

Roghair, I., Lau, Y. M., Deen, N. G., Slagter, H. M., Baltussen, M. W., Van Sint Annaland, M. and Kuipers, J. A. M. (2011), 'On the drag force of bubbles in bubble swarms at intermediate and high reynolds numbers', Chemical Engineering Science 66, 3204-3211.

Rusche, H. and Issa, R. (2000), The effect of voidage on the drag force on particles, droplets and bubbles in dispersed two-phase flow, in '2nd Japanese European Two-Phase Flow Meeting.', Tsukuba, Japan.

Rzehak, R. and Krepper, E. (2013), 'CFD modeling of bubble-induced turbulence', International Journal of Multiphase Flow 55(Supplement C), 138-155.

Sasaki, S., Hayashi, K. and Tomiyama, A. (2016), 'Effects of liquid height on gas holdup in air-water bubble column', Experimental Thermal and Fluid Science 72, 67-74.

Sasaki, S., Uchida, K., Hayashi, K. and Tomiyama, A. (2017), 'Effects of column diameter and liquid height on gas holdup in airwater bubble columns', Experimental Thermal and Fluid Science 82, 359-366.

Shah, Y. T., Kelkar, B. G., Godbole, S. P. and Deckwer, W. (1982), 'Design parameters estimations for bubble column reactors', AIChE Journal 28(3), 353-379.

Shaikh, A. and Al-Dahhan, M. (2013), 'Scale-up of bubble column reactors: A review of current state-of-the-art', Industrial $\mathcal{E}$ Engi- neering Chemistry Research 52(24), 8091-8108

Simonnet, M., Centric, C., Olmos, E. and Midoux, N. (2008), 'CFD simulation of the flow field in a bubble column reactor: Importance of the drag force formulation to describe regime transitions', Chemical Engineering and Processing 47, 1726-1737.

Sugrue, R. M. (2017), A robust momentum closure approach for multiphase computational fluid dynamics applications, $\mathrm{PhD}$ thesis, Massachusetts Institute of Technology.

Tabib, M. V., Roy, S. A. and Joshi, J. B. (2008), 'CFD simulation of bubble column - An analysis of interphase forces and turbulence models', Chemical Engineering Journal 139(3), 589-614.

Tomiyama, A. (1998), 'Struggle with computational bubble dynamics', Multiphase Science and Technology 10(4), 369.

Vaidheeswaran, A. and de Bertodano, M. L. (2017), 'Stability and convergence of computational eulerian two-fluid model for a bubble plume', Chemical Engineering Science 160, 210-226.

Wallis, G. B. (1969), One-dimensional two-phase flow, 1st edn, McGraw-Hill, New York.

Wilkinson, P. M., Spek, A. P. and van Dierendonck, L. L. (1992), 'Design parameters estimation for scale-up of high pressure bubble column', 38, 544-554.

Xue, J. (2004), Bubble velocity, size and interfacial area measurements in bubble columns, PhD thesis, Sever Institute of Washington University.

Yao, W. and Morel, C. (2004), 'Volumetric interfacial area prediction in upward bubbly two-phase flow', 47, 307-328.

Zhang, D. (2007), Eulerian modeling of reactive gas-liquid flow in a bubble column, PhD thesis, Enschede, The Netherlands.

Zhang, D., Deen, N. G. and Kuipers, J. A. M. (2006), 'Numerical simulation of dynamic flow behavior in a bubble column: A study of closures for turbulence and interface forces', Chemical Engineering Science 61, 7593-7608. 